\title{
Analisis konservasi kawasan banjir di Jakarta Pusat (studi kasus Kecamatan Gambir)
}

\author{
Titien Suryanti ${ }^{1 *}$, Olivia Seanders ${ }^{1}$ \\ 1. Jurusan Arsitektur Lanskap, Fakultas Arsitektur Lanskap dan Teknologi Lingkungan, Universitas Trisakti, \\ Jalan Kyai Tapa 1, Jakarta, Indonesia \\ *E-mail: titiensr@trisakti.ac.id
}

\begin{abstract}
Conservation Analysis of Flood Area In Jakarta Pusat (Case Study: Gambir Sub-District). The city's development as one of the primary government centers has experienced various changes in the land's physical environment, which are increasingly dense by various infrastructures to impact the quality of people's lives and the environment. This study aims to achieve a healthy ecological system by conserving flood-prone areas as human needs for a healthy environment. This research took place in the Gambir Subdistrict, Central Jakarta Municipality, Special Region of Jakarta Province, with an area of $7.59 \mathrm{~km} 2$. The method used in this paper is a descriptive analysis using secondary data. Based on the analysis of land use maps, green open space maps, land subsidence maps and topography, yielded three Conservation Area categories in Gambir District, namely (a) High Category, covering urban villages (Kelurahan) of Kebon Kelapa and Gambir (b) Medium category, covering urban villages of Duri Pulo and Cideng (c) Low Category, covering urban villages of North Petojo and South Petojo areas.
\end{abstract}

Keywords: conservation, flood area, city, Gambir Subdistrict

\section{Pendahuluan}

Seiring dengan perkembangan kota, DKI Jakarta sebagai salah satu pusat pemerintahan primer, mengalami berbagai perubahan lingkungan fisik lahan yang semakin padat dengan berbagai infrastuktur sehingga berdampak terhadap kualitas kehidupan masyarakat dan lingkungan. Laju pemanfaatan tanah semakin terus meningkat dan fragmentasi pada Ruang Terbuka Hijau di DKI Jakarta mendorong perencanaan lanskap untuk mempertimbangkan pendekatan strategis bagi konservasi dan pembangunan. Hal ini menunjangpertumbuhan perkotaan dan efisiensi dalam peruntukan lahan di DKI Jakarta.Pada saat ini area metropolitan menghadapi masalah besr antara lain, hilangnya vegetasi alami dan ruang terbuka, dan secara keseluruhan berkurangnya lahan basah dan habtat hidupan liar yang menimbulkan permaalahan lingkungan (Monica et al., 2010).

Pendekatan dalam skala lansekap untuk perencanaan konservasi merupakan suatu dasar dari perencanaan infrastruktur hijau. Hal ini, merupakan salah satu pondasi bagi jaringan keanekaragaman hayati regional. Berbagai jenis konservasi berbasis pada perencanaan telah digunakan, karena adanya rencana bagi ekosistem alami, dan keprihatinan terhadap fragmentasi habitat-habitat setempat yang harus dilindungi.

DKI Jakarta, khususnya Kecamatan Gambir, telah berkembang pesat baik secara fisik, sosial dan ekonomi, seiring dengan perkembangan suatu wilayah kota. Untuk itu, perlu diteliti aspek-aspek yang mendukung perkembangan suatu kota. Salah satu aspek yang akan diteliti dalam konteks studi ini adalah rawan bahaya banjir sebagai bagian dari pendekatan perencanaan lansekap kota, serta aspek - aspek yang terkait.

Kecamatan Gambir, merupakan salah satu kecamatan di kawasan DKI Jakarta yang merupakan salah satu kecamatan yang hampir keseluruhan terletak berbagai dengan pusat pemerintahan primer. Kecamatan Gambir DKI Jakarta memiliki luas wilayah $7.59 \mathrm{~km} 2$ (Gambir dalam Angka, 2015). Dari luas tersebut pertumbuhan fisik ruang terbuka hijau, yaitu seluas $0.76 \mathrm{Ha}$ (10\% dari luas keseluruhan) (Gambir dalam Angka 2015). Berdasarkan Gambir Dalam Angka tahun 2017 jumlah penduduk kecamatan gambir 180.301 jiwa.

Keberadaan ruang terbuka hijau sangat diperlukan bagi wilayah perkotaan seperti Kecamatan Gambir, Jakarta Pusat, DKI Jakarta. Selain menambah nilai estetika dan keasrian kota, juga berfungsi sebagai salah satu dasar dari perencanaan infrastruktur hijau yang berkaitan dengan konverasi untuk Kawasan Banjir. Oleh karena itu, diperlukan suatu analisa tentang Kajian Konservasi Kawasan Banjir di Jakarta Pusat dengan 
Kecamatan Gambir sebagai area penelitian. Konservasi bertujuan untuk menjaga kelangsungan keanekaragaman spesies, dan memelihara keanekaragaman genetik dalam suatu spesies, termasuk juga pemeliharaan biosfer. Pendekatan perencanaan untuk meminimalisir kerusakan habitat atau hilangnya spesies yaitu (Marsh, 1997): (i) Fokus pada lokasi kritis, karena tempat yang di pilih untuk manajemen harus yang memenuhi preferensi organisme. (ii) Memperhatikan skala/konektifitas. Tujuan konservasi secara hukum tertuang dalam Undang-Undang Republik Indonesia Nomor 5 Tahun 1990 tentang Konservasi Sumber Daya Alam Hayati dan Ekosistemnya. Jika keanekaragaman hayati tidak selaras dengan kehidupan manusia, maka di kemudian hari beberapa tanaman dan fauna asli akan punah . (Crane et al., 2005)

Kegiatan merencanakan suatu lansekap merupakan suatu proses pemikiran dari suatu ide, gagasan atau konsep kehidupan manusia/masyarakat ke suatu bentuk landsekap atau bentuk alam yang nyata secara berkelanjutan. Landscape Planning. The decisions making, technical and design proceses associated with the deteminination of land uses and the utilization of terrestrial resources (Marsh, 1997).

Pada 'UU No. 26 Tahun 2007 tentang Penataan Ruang', dapat dilihat mengenai pentingnya ketersedian ruang terbuka hijau serta pemanfaatannya dengan ketentuan luasan minimal sekitar 30 (tiga puluh) persen dari luas wilayah kota. Sedangkan dalam PERMEN PU No. 05/PRT/M/2008, adapun pengertian ruang terbuka hijau sebagai area memanjang/jalur dan atau mengelompok, yang penggunaannya lebih bersifat terbuka, tempat tumbuh tanaman, baik yang tumbuh tanaman secara alamiah maupun yang sengaja ditanam.

Ruang Terbuka Hijau (RTH), memiliki beragam fungsi, sebagai berikut, fungsi utama (intrinsik) yaitu fungsi ekologis, fungsi sosial dan budaya, fungsi ekonomi, fungsi estetika. RTH berdasarkan fungsinya, yang terbagi atas : (i) Manfaat langsung (dalam pengertian cepat dan bersifat tangible), yaitu membentuk keindahan dan kenyamanan (teduh, segar, sejuk) dan mendapatkan bahan-bahan untuk dijual (kayu, daun, bunga, buah); (ii) Manfaat tidak langsung (berjangka panjang dan bersifat intangible), yaitu pembersih udara yang sangat efektif, pemeliharaan akan kelangsungan persediaan air tanah, pelestarian fungsi lingkungan segala isi flora dan fauna yang ada (konservasi hayati atau keanekaragaman hayati). Ruang terbuka hijau jika di bangun dalam skala yang luas dan melintasi berbagai fungsi lahan, dapat berkontribusi dalam melestarkan proses alam dan fungsi fungsinya, serta mendukung pertumbuhan keberlanjutan kota (Luis dan Laura, 2012)

\section{Metode Penelitian.}

\subsection{LokasI dan Waktu Penelitian}

Penelitian ini mengambil lokasi di Kecamatan Gambir, Kotamadya Jakarta Pusat, Prov. DKI Jakarta, dengan luasaan $7.59 \mathrm{~km} 2$ dengan batas-batas wilayah penelitian sebagai berikut (Gambir Dalam Angka, 2015), (i) Sebelah utara berbatasan dengan Jl. Sukarjowiryopranoto, JL. KH. Hasyim Ashari, Jl. Duri Barat s.d Tanggul Kali Banjir Kanal., (ii) Sebelah selatan berbatasan dengan Jl. Jati Batu, Jl. Kebon Sirih Prapatan, s.d. Jembatan Kwitang, (iii) Sebelah barat berbatasan dengan Kali Banjir Kanal Barat,dan (iv) sebelah timur berbatasan dengan Pintu Kreta Api Krekot, Jl. Perwira A, Kali Ciliwung. Penelitian dilakukan selama kurang lebih 1 tahun mulai bulan Oktober 2017 sampai dengan Agustus 2018.

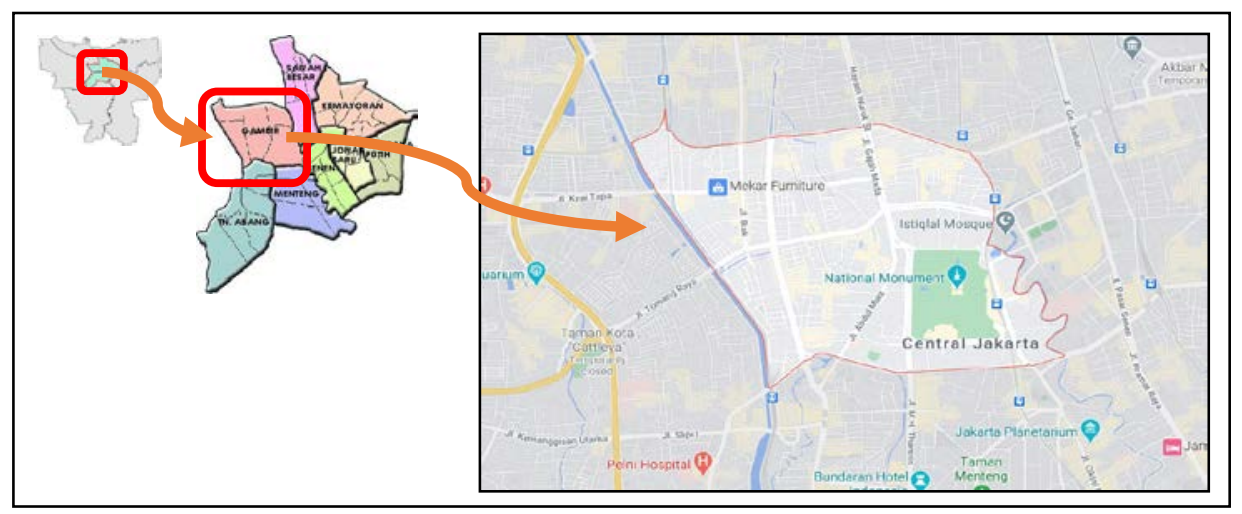

Gambar 1. Peta Lokasi Penelitian (Wikipedia 2020, darkwin98 Wordpress 2020, Google Map 2020) 


\subsection{Metode Penelitian}

Metode yang digunakan dalam penelitian ini adalah deskriptif analisis dengan menggunakan data sekunder. Pengambilan sampel dilakukan secara purposive sampling, dimaksudkan untuk memperoleh informasi mengenai keberadaan permasalahan rawan Banjir di Kecamatan Gambir serta bagaimana mengkonservasikannya. Penentuan Sampel ditentukan dengan mempertimbangkan bahwa pihak terkait terpilih adalah pihak yang berperan dalam memberikan informasi berdasarkan keterkaitan di lokasi peneliti dengan mempertimbangkan isu rawan banjir serta pertimbangan konservasi di lokasi tersebut; serta pengaruhnya didalam komunitas lokasi penelitian, minimal berpendidikan SMU atau lebih serta memahami pentingnya keberadaan Ruang Terbuka Hijau bagi suatu lingkungan.

\subsubsection{Teknik Pengambilan Data .}

(a) Suvey lapangan, dilakukan untuk mendapatkan (i) data primer, dalam penelitian ini berupa data visual tentang kondisi Kecamatan Gambir secara umum (ii) data sekunder, dalam penelitian berupa data administrasi, data fisik dan biofisik, data sosial demografi dan data lainnya, seperti: Peta administrasi Kecamtan Gambir, Rencana Tata Ruang Wilayah DKI Jakarta 2030, Peraturan-perundangan yang terkait dengan Ruang Terbuka Hijau, Gambir Dalam Angka, Jakarta Pusat, Badan Pusat Stastistik,

(b) Studi literatur, dilakukan untuk mendapatkan data tentang peraturan pemerintah, kebijaksanaan, dan mendapatkan landasan teori untuk menemukan akar permasalahan dan tindakan penanggulangan yang tepat terhadap rawan banjir.

\subsubsection{Analisis Data}

Pada penelitian ini adalah analisis deskriptif kualitatif. Analisis ini dilakukan untuk menggambarkan keadaan fisik dan visual keberadaan data pada Kecamatan Gambir. Data hasil wawancara, akan dipergunakan sebagai dasar dari analisis secara deskriptif yang dilakukan guna memberikan gambaran akan keberadaan Kualitas Ruang Terbuka Hijau yang seharusnya dapat diwujudkan di lokasi penelitian serta kaitannya dengan rawan Banjir.

Dalam melakukan analisis spatial kawasan konservasi kawasan Jakarta Pusat, Kecamatan Gambir dilakukan dengan Metoda Overlay (tumpang tindih) secara digital yang dikembangkan oleh lan McHarg (1968), yaitu metoda yang menggunakan beberapa peta super posisi dari satuan geografis yang sama. Dalam studi ini satuan analisis yang digunakan adalah satuan region dan satu kesatuan wilayah konservasi. Adapun peta yang digunakan, antara lain: (a) Peta Dasar, (b) Peta Jaringan Jalan, (c) Peta Penggunaan Lahan, (d) Peta Ruang Terbuka Hijau, (e) Peta Penurunan Tanah, (f) Peta Sistem Penyediaan Air Bersih.

\section{Hasil dan Pembahasan}

\subsection{Kondisi umum dan Lokasi Penelitian}

Kecamatan Gambir merupakan salah satu kecamatan yang berada di kota administrasi Jakarta Pusat. Pada Rencana Detail Tata Ruang dan Peraturan Zonasi tahun 2014, terdapat beberapa tujuan penataan ruang di kecamatan Gambir, antara lain terwujudnya pengembangan taman kotalingkungan dan jalur hijau sebagai prasarana resapan air, pengendali polusi udara, sosial, dan keindahan kota. Dengan rencana pola ruang pada zona fungsi budidaya Kecamatan Gambir terdiri dari: 1) Zona terbuka hijau lindung; 2) Zona taman kota/lingkungan; 3) Zona pemakaman; 4) Zona jalur hijau; 5) Zona hijau rekreasi

Kelurahan Gambir merupakan kelurahan dengan wilayah sangat luas yaitu 258 hektar dengan distribusi presentase yaitu 34,03\%, kemudian diikuti oleh kelurahan Cideng dengan luas 126 hektar dimana distribusi presentase adalah $16,65 \%$ sedangkan kelurahan yang memiliki wilayah dengan luasan yang kecil adalah kelurahan Kebon Kelapa dengan luas 78 hektar dan kelurahan Duri Pulo yaitu 71 hektar. 


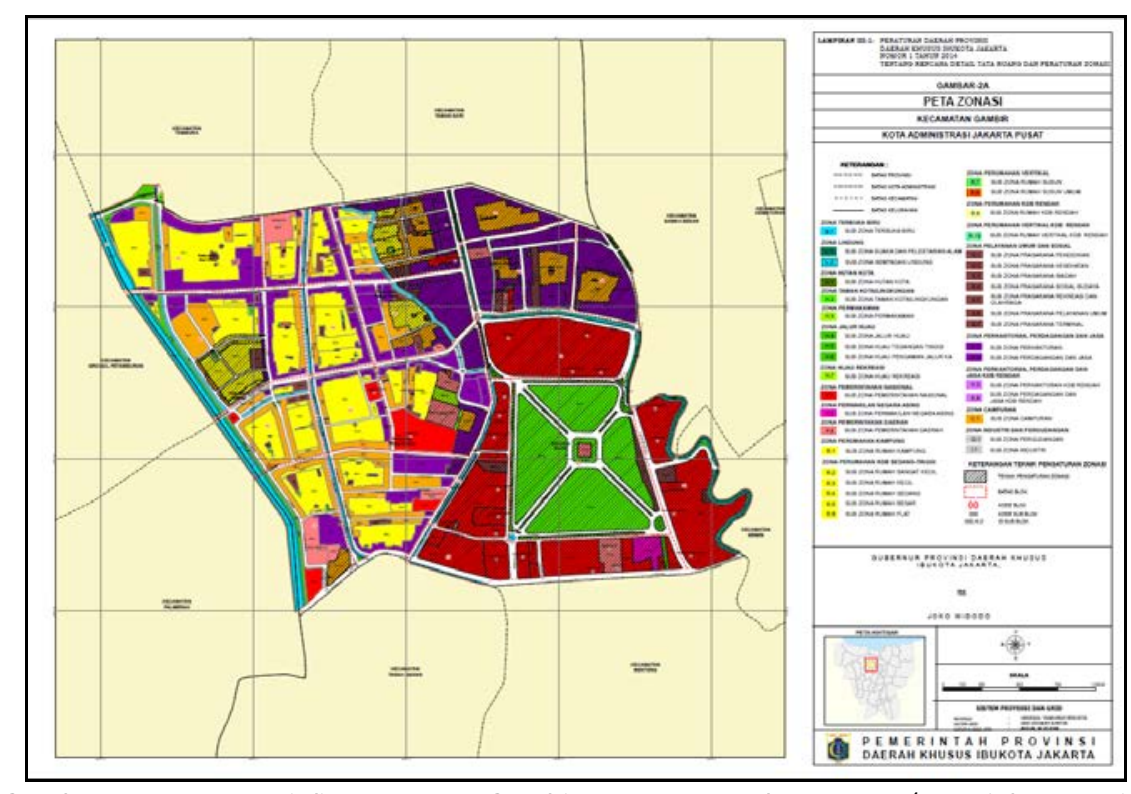

Gambar 2: Peta Zonasi di Kecamatan Gambir RTRW DKI Jakarta 2030 (www.jakarta.go.id)

Pada tahun 2017 kecamatan Gambir memiliki total jumlah penduduk sebanyak 180.301 jiwa. Jumlah penduduk terbesar berada di Kelurahan Duri Pulo 25,13 \%, kemudian diikuti oleh kelurahan Petojo Utara 21,82\%, Kelurahan Cideng.19,21\%, Kelurahan petojo selatan 17,89\%. Sedangkan kelurahan yang memiliki jumlah penduduk paling sedikit berada di keluraha Gambir.3,17\%. (Gambir dalam angka 2017)

Tabel 1. Luas Wilayah Menurut Kelurahan di Kecamatan Gambir

\begin{tabular}{clcc}
\hline No & \multicolumn{1}{c}{ Kelurahan } & Luas Wilayah $(\mathrm{Ha})$ & Distribusi Presentase $(\%)$ \\
\hline 1. & Cideng & 126 & 16,65 \\
2. & Duri Pulo & 71 & 9,32 \\
3. & Gambir & 258 & 34,03 \\
4. & Kebon Kelapa & 78 & 10,29 \\
5. & Petojo Selatan & 114 & 14,97 \\
6. & Petojo Utara & 112 & 14,74 \\
\hline & Total & 759 & 100 \\
\hline
\end{tabular}

Sumber: Gambir Dalam Angka, 2013 dan 2017

\subsection{Analisis Ruang Terbuka Hijau (RTH)}

Kecamatan Gambir di tahun 2013, memiliki luas ruang terbuka hijau sebesar 90,28 hektar, luasan ini terdiri dari tipe taman kota, taman lingkungan dan jalur hijau. Ruang terbuka hijau didalam pengelolaan masih dikelolah oleh Dinas Kehutanan DKI Jakarta.Sedangkan di tahun 2017, Luasan ruang terbuka hijau di kecamatan Gambir mengalami penurunan menjadi 76,45 hektar, luasan ini terdiri atas tiga tipe ruang terbuka hijau publik, antara lain taman kota, taman lingkungan, dan jalur hijau. Taman kota memiliki luas 63,14 hektar, taman lingkungan memiliki luas 3,81 hekar dan jalur hijau memiliki luas 9,50 hektar. Pengelolaan ruang terbuka hijau di kecamatan Gambir berada dibawah pengelolaan Suku Dinas Kehutanan Jakarta Pusat.

Ruang Terbuka Hijau di kecamatan Gambir mempunyai beragam peran dan fungsi bagi masyarakat antara lain, sebagai tempat rekreasi, tempat berolahraga, tempat bersosialisasi, sebagai peneduh dan sebagai paru- paru kota.

Di wilayah Jakarta Pusat, total ruang terbuka hijau pada tahun 2013 adalah 350,47 hektar, sedangkan pada tahun 2017 ruang terbuka hijau mengalami peningkatan menjadi 360,98 hektar. Di Jakarta Pusat, terjadi penambahan luas ruang terbuka hijau selama 5 tahun terakhir dengan total penambahannya yaitu 10,51 hektar.

Ruang Terbuka Hijau yang sudah ada dipertahankan dan dikembangkan sebagai area konservasi dengan mempertimbangkan berbagai aspek, yaitu (a) Beberapa RTH yang dapat dikembangkan di lingkungan 
perkantoran, (b) Penurunan tinggi muka tanah di bagian sebelah utara kecamatan Gambir hal ini menyebabkan adaya indikasi rawan banjir., (c) Perlu dipertahankan beberapa RTH yang sudah ada, RTH, jalur hijau tepi sungai dan taman lingkungan di bagian selatan Kelurahan Cideng karena merupakan pengendali tata air yang berperan dalam mewujudkan konservasi pada daerah rawan banjir.

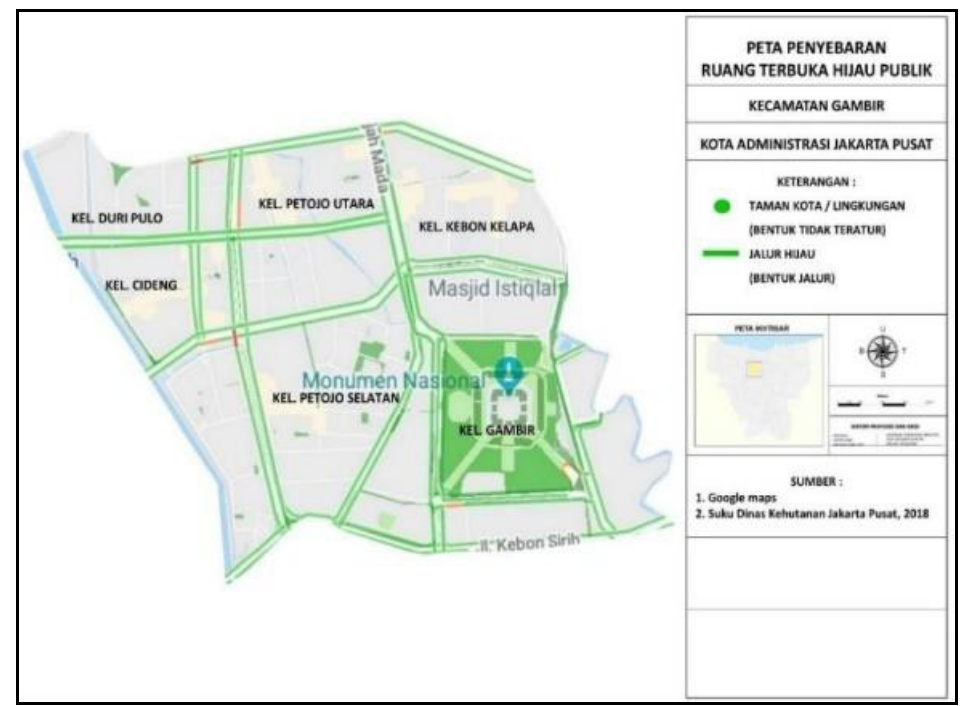

Gambar 3. Peta Penyebaran RTH di Kecamatan Gambir RTRW DKI Jakarta 2030 (Sahalessy, 2019)

\subsection{Analisis Hidrologi dan Rawan Bencana Banjir}

Ketersediaan air di Kecamatan Gambir awalnya berasal dari sumur-sumur dangkal dengan kualitas yang aman untuk digunakan sebagai air minum. Terdapat tiga jenis sumber air di Kecamatan Gambir, yaitu sungai, PDAM dan air tanah dalam (deep well). PDAM digunakan sebagai penyedia air utama bagi masyarakat Kecamatan Gambir. Sumber air PDAM ditampung di reservoir penampung air bersih untuk kemudian disalurkan langsung ke area pelayanan masing-masing tanpa proses pengolahan.

Berdasarkan hasil kajian, Bencana yang mengancam Kecamatan Gambir dapat digolongkan pada dua kategori, yaitu: 1) Rawan Bencana, tingkat sangat rendah, pada Kecamatan Gambir bagian utara, timur serta Monas. 2) Rawan Bencana, yang tingkat rendah pada bagian selatan dan Barat Kecamatan Gambir.

\subsection{Penurunan Muka Tanah dan Penggunaan Lahan}

Penurunan muka tanah (Land subsidence), sebuah fenomena alam di kota-kota besar yang terjadi dengan pemerosotan secara bertahap atau anjloknya permukaan secara tiba-tiba seiring dengan pergerakan material bumi. Peristiwa ini disebabkan oleh berbagai hal berbeda namun semua prosesnya berhubungan erat dengan air tanah.

Di dalam Wirawan dkk (2019) berdasarkan Whittaker dan Reddish (1989), secara garis besar penurunan muka tanah bisa disebabkan oleh beberapa hal antara lain, (i) Penurunan muka tanah alami (natural subsidence) disebabkan oleh proses-proses geologi seperti siklus geologi, sedimentasi daerah cekungan, (ii) Penurunan muka tanah yang disebabkan oelh pengambilan bahan cair dari dalam tanah seperti air tanah or minyak bumi, (iii) Penurunan muka tanah yang disebabkan oleh adanya beban-beban berat diatasnya seperti struktur bangunan sehingga lapisan-lapisan tanah dibawahnya mengalami kompaksi/konsolidasi, sering disebut dengan settlement subsidence, (iv) Penurunan muka tanah akibat pengambilan bahan padat dari tanah, seperti halnya aktivitas penambangan.

Pada Kecamatan Gambir terutama kawasan kelurahan Petojo Utara dan sebagian kelurahan Kebun Kelapa serta kelurahan Gambir bagian utara, terjadi sebesar 80 s.d. $100 \mathrm{~cm}$. Sedangkan pada kelurahan Kebun Kelapa, terjadi penurunan dengan 100 s.d. $120 \mathrm{~cm}$ namun aman dari bencana. Dengan ada potensi penurunan tanah, maka dapat terjadi kemungkin terjadi potensi rawan banjir, sehingga pada daerah yang mengalami 
penurunan muka tanah mulai dari $80 \mathrm{~cm}$ sampai dengan $120 \mathrm{~cm}$, perlu mempertimbangkan konservasi penuh. Kecamatan Gambir dengan luas wilayah $7.59 \mathrm{~km}^{2}$. Dari luas wilayah tersebut pertumbuhan fisik kota ditunjukkan oleh besarnya kawasan terbangun kota, sehingga sisanya sangat strategis untuk dapat dikonsolidasi dengan baik ke dalam wilayah terbangun kota yang ada melalui perencanaan kota yang sesuai dengan Rencana Tata Ruang Wilayah (RTRW) dan Rencana Detail Tata Ruang (RDTR). Data terakhir menunjukkan bahwa pemanfaatan lahan di Kecamatan Gambir meliputi: 1) Pemukiman teratur dan tidak teratur, 2) Perkantoran, 3) Pemerintahan, 4) Ruang Terbuka Hijau

Penggunaan lahan di kecamatan Gambir terdiri atas dua jenis penggunaan yaitu sebagai kawasan lindung dan sebagai kawasan budidaya. Kawasan lindung sendiri terdiri atas ruang terbuka hijau dan sungai, sedangkan kawasan budidaya terdiri atas permukiman, perkantoran, perdagangan dan jasa, serta pemerintahan. Pada peta di bawah ini, dapat dilihat bahwa penggunaan lahan di kecamatan Gambir sangat didominasi oleh kawasan budidaya, dimana kawasan lindung seperti ruang terbuka hijau masih sangat sedikit. Terdapat pula lahan - lahan kosong yang tersebar di beberapa kelurahan di kecamatan Gambir, dimana lahan tersebut sesuai untuk dikembangkan sebagai ruang terbuka hijau

\subsection{Rencana Pengembangan Kawasan Konservasi}

Rencana Pengembangan Kawasan Konservasi Pusat pemerintahan, Kecamatan Gambir. Berdasarkan hasil analisa peta penggunaan lahan, peta ruang terbuka hijau, peta penurunan muka tanah dan tofografi,melalui proses overlay, menghasilkan tiga kategori Area Konservasi pada Kecamatan Gambir, yaitu (a) Kategori Tinggi, meliputi kelurahan Kebon Kelapa dan Kelurahan Gambir, dimana pada kedua lokasi tersebut terdapat daerah konservasi jalur hijau sempadan sungai Ciliwung, serta ada Taman Monas, serta area hijau di daerah pusat pemerintahan (Sekretariat Negara, Istana Negara, Pertamina dan Gereja Immanuel) selain itu adapula jalur hijau jalan di jalan protokol. (b) Kategori Sedang, meliputi Kelurahan Duri Pulo serta Kelurahan Cideng, pada kedua lokasi tersebut terdapat konservasi jalur hijau sempadan sungai Kanal Banjir Barat, serta adanya peninggalan daerah konservasi berupa pemakaman kuno Belanda. (c) Kategori Rendah, meliputi daerah Petojo Utara dan Petojo Selatan, banyak terdapat penggunaan lahan untuk dijadikan kawasan pemukiman serta kawasan perdagangan, sehingga kemungkinan Ruang Terbuka Hijau yang dapat dikembangkan sangat kecil, sebab hamper tidak ada ruang tersisa untuk dijadikan ruang terbuka hijau, seperti banyak rumah tinggal yang perkarangannya dijadikan perkerasan untuk area tambahan parkir kendaraan.

RENCANA PENGEMBANGAN AREA KONSERVASI KECAMATAN GAMBIR, DKI JAKARTA

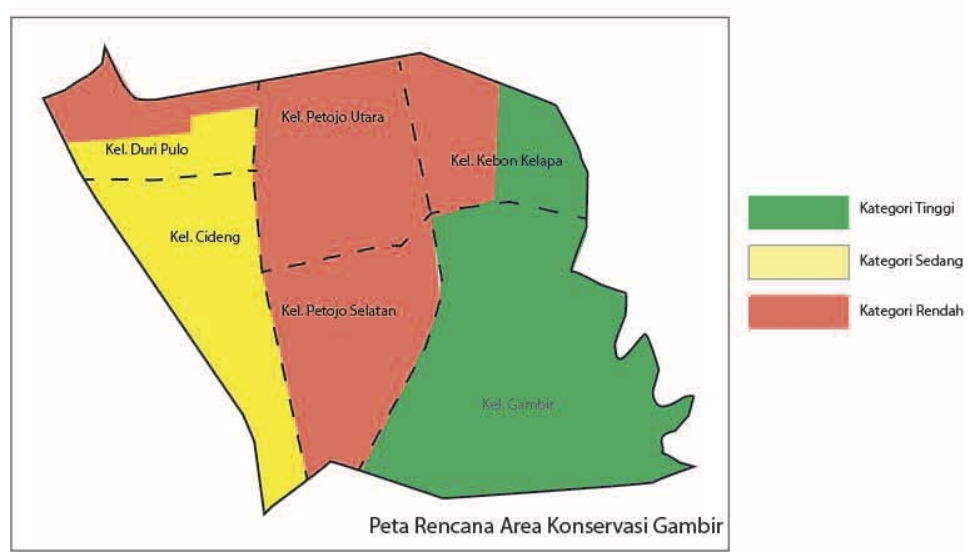

Gambar 4. Peta Rencanan Area Konservasi Kecamatan Gambir

Rencana pengembangan Kawasan konservasi di kecamatan Gambir, maka pada area dengan kategori tinggi, konservasi perlu di prtahankan dengan tidak melakukan pembangunan.Agar rencana tersebut dapat berhasil maka, area konservasi dengan kategori tinggi di dalam penggunaan lahan, diusulkan tetap sebagai Kawasan lindung. 


\section{Simpulan}

Rencana Pengembangan Kawasan Konservasi Pusat pemerintahan, Kecamatan Gambir, berdasarkan hasil analisa peta penggunaan lahan, peta ruang terbuka hijau, peta penurunan muka tanah dan tofografi, menghasilkan tiga kategori Area Konservasi pada Kecamatan Gambir yaitu ; i). Kategori Tinggi, ii). Kategori Sedang, iii). Kategori Rendah.

Ruang terbuka hijau, Konservasi di Kecamatan Gambir Kategori Tinggi terdapat pada daerah konservasi jalur hijau sempadan sungai Ciliwung, Taman Kota Monas, serta area hijau di daerah pusat pemerintahan. Selain itu adapula jalur hijau jalan di jalan protokol; Ruang terbuka hijau, Konservasi di Kecamatan Gambir Kategori Sedang terdapat pada jalur hijau sempadan sungai Kanal Banjir Barat, dan pada daerah pemakaman kuno Belanda; Ruang Terbuka Hijau Konservasi di Kecamatan Gambir Kategori Rendah dapat dikembangkan sangat kecil, sebab hampir tidak ada ruang tersisa untuk dijadikan ruang terbuka hijau, banyak rumah tinggal yang perkarangannya dijadikan perkerasan.

\section{Daftar Pustaka}

Anonim, 2010, Peta Jakarta Pusat, https://darkwin98.wordpress.com/2010/12/08/kota-administrasi-jakartapusat/. Diakses 2020

Badan Pusat Statistik (BPS). 2015. Kecamatan Gambir Dalam Angka 2015. Katalog BPS 11020013173. Website http://www.bps.go.id/, diakses pada tahun 2019

Badan Pusat Statistik (BPS). 2015. Kecamatan Gambir Dalam Angka 2017. Katalog BPS 1102001.3173080. Website http://www.bps.go.id/, diakses pada tahun 2020

Crane, P.,Ann K. 2005. Nature in the metropolis. Science.308.1225

Keputusan Menteri Pekerjaan Umum Republik Indonesia Nomor 05/PRT/M/2008 tentang Pedoman Penyediaan Dan Pemanfaatan Ruang Terbuka Hijau Di Kawasan Perkotaan

Luis, L.and Laura, C. 2012. The Role of Urban Parks to Enhance Metropolitan Sustainability; The Case of Oporto. International Journal of Energy and Environment Issue 4.vol 6.

Monica, D, Ines G, Mihaela N. 2010. Sustainable Natural Landscape Management within Buchares Metropolitan area. Geography Journal 62 (2010)1.21.32

Marsh, W. 1997. Landscape Planning: Environmental Planning Environmental Application, America. John Wiley \& Sons, Inc. 3th edition. New Jersey.

Michell, W.B. 1989. Geography and Resource Analysis, Longman Scientific and Technical; 2nd edition, New York, USA.

Peraturan Daerah Provinsi Daerah Khusus Ibukota Jakarta Nomor 1 Tahun 2012 Tentang Rencana Tata Ruang Wilayah 2030

Sahalessy, A, Krisantia,I , Budiyanti, RBB. 2019. Prosiding Seminar Nasional Pembangunan Wilayah dan Kota Berkelanjutan dengan judul Evaluasi Ketersediaan Ruang Terbuka Hijau Publik Menurut Peraturan Menteri Pekerjaan Umum Nomor 5 Tahun 2008 di Kecamatan Gambir, Jakarta Pusat. Hal 283 - 288. DOI : 10.25105/pwkb.v1i1.5291

Shalih, O. (2019, December 1). Analisis Fungsi Banjir Kanal Timur : Dalam Menanggulangi Banjir di Wilayah DKI Jakarta bagian Timur. https://doi.org/10.31227/osf.io/j8awk

Steiner, F. 2000, The Living Landscape: An Ecological Approach to Landscape Planning, 2nd Edition, USA

Undang-Undang Republik Indonesia Nomor 26 Tahun 2007 Tentang Penataan Ruang

Wirawan, A., Yuwono, B., \& Sabri, L. (2019). Pengamatan Penurunan Muka Tanah Kota Semarang Metode Survei Gnss Tahun 2018. Jurnal Geodesi Undip, 8(1), 418-427. Retrieved from https://ejournal3.undip.ac.id/index.php/geodesi/article/view/22772 